\title{
Analysis of images recorded during welding processes
}

\author{
by A. Bzymek*, A. Czupryński**, M. Fidali*, W. Jamrozik and A. Timofiejczuk* \\ ${ }^{*}$ Department of Fundamentals of Machinery Design, Silesian University of Technology at Gliwice, Poland \\ ${ }^{* \star D}$ Department of Welding, Silesian University of Technology at Gliwice, Poland
}

\begin{abstract}
In the paper elements of a system of assessment of a welding process and welded joints have been presented. The system was based on the application of one thermovision and two CCD cameras. In the paper exemplary results of processing and analysis of thermal and ordinary images have been discussed.
\end{abstract}

\section{Introduction}

The course of a welding process significantly influences the quality of welds. In order to obtain high quality joints proper parameters of welding process are required to be stable. In most cases by a correct welded joints one assumes the joints which are characterized not only by required mechanical properties but also by aesthetic quality. While the selection of proper welding parameters for an experienced welder does not make difficulties, the stability of these parameters is often not easy to be ensured. Abnormality of the process is caused by numerous factors which are often random. Examples are instability of passing of a filler wire, smudges of dirt, inaccuracy of preparation of element edges, deformations of elements as effects of thermal phenomena. These factors are reasons of common welding defects, such as excessive undercuts, partial or lack of joint penetration, cracks, overheatings, excessive convexity or concavity of a face of weld, blisters, bubbles and holes [4-6,10,14-20].

Maintenance of the high quality welding process and welds can be obtained by means of constant control of process parameters. One describes different approaches to the process inspection. Examples are measurements of amperage, voltage and flow of shielding gas [17, 23]. An alternative way of maintenance the welding process is to employ vision control $[3,7,13,22]$. By means of a vision system one is able to observe the process both in Infrared and visible electromagnetic band. Gathered images can be analyzed and objects identified in images can be recognized and assessed. Such the approach is enumerated in bibliography as one of the most promising ways of maintenance of welding processes and assessment of welds $[11,23]$. The most essential aspect of the application of such systems is a possibility of rapid identification of abnormalities occurring during the process. It is especially important in case of huge lots of products. It happens that the same failures can occur repeatedly, what is often related to significant production losses.

The main problem concerning the application of vision systems seems to be a proper image analysis. In welding industry methods based on image analysis are being used for seam tracking [13,24], control of a weld pool size [21], control of weld geometry and assessment of weld quality [3] as well as for adaptive control of welding processes [25].

Issues described in the paper are a part of investigations aimed at development of a system of controlling automatic welding processes. According to this approach, the vision system consists of three cameras. A crucial role is played be an IR camera, which observes a welding arc and pool, and the joint that is getting cold. Observation of the process is also aided by two CCD cameras, which record correspondingly images representing the arc and the joint. There are two goals of image analysis. The first one is to asses the stability of welding process, which is performed by means of determination of geometrical parameters of the arc. Secondly, some common defects of joints are supposed to be detected. It should be stressed that the application of IR camera lets us to detect not only surface defects but also defects and phenomena that do not manifest themselves on the surface.

Presented experiments were carried out with the use of series of samples divided into some groups characterized by: correctly prepared surface, surface covered with rust, and parts covered with some impurities [2]. A Concept of general approach applied in the system has been presented in [8].

\section{Overview of the vision system}

The welding process can be realized with the use of different devices. In industrial production automated and equipped with robots stands are commonly used, they enable MIG or MAG welding. Usually in such automated processes elements to be joined move and a welding device passing the filled wire is motionless. The vision system elaborated within the framework of the research described in the paper has been assigned to such processes. General overview of the system was presented in figure 1. The system let us to record, archive, process, analyze and recognize two types of images acquired by three presented cameras:

- hot area that includes sub-areas of arc, metal in fluid and solidification phases and welded elements,

- self-cooling area consisting of weld and welded elements sub-areas.

The system has included hardware and software parts [8]. The hardware part has consisted of a set of cameras and light sources mounted on a special support. The main task of this part was to observe the process by means of IR camera (VarioCam by Infratec, resolution in IR field 320x240px, spectral range 8-13 $\mu \mathrm{m}$, 
temperature measurement range $-40-1200 \mathrm{0C}$, thermal resolution better than $100 \mathrm{mK}$, length of lens focal $25 \mathrm{~mm}$ and vision field FOV $32^{\circ} \times 25^{\circ}$, max. speed of image recording $50 \mathrm{f} / \mathrm{s}$ ) and two CCD industrial cameras (cameras by ImagingSource, resolution 786x1024px, focal length $50 \mathrm{~mm}$, max. speed of image recording $30 \mathrm{f} / \mathrm{s}$ ).

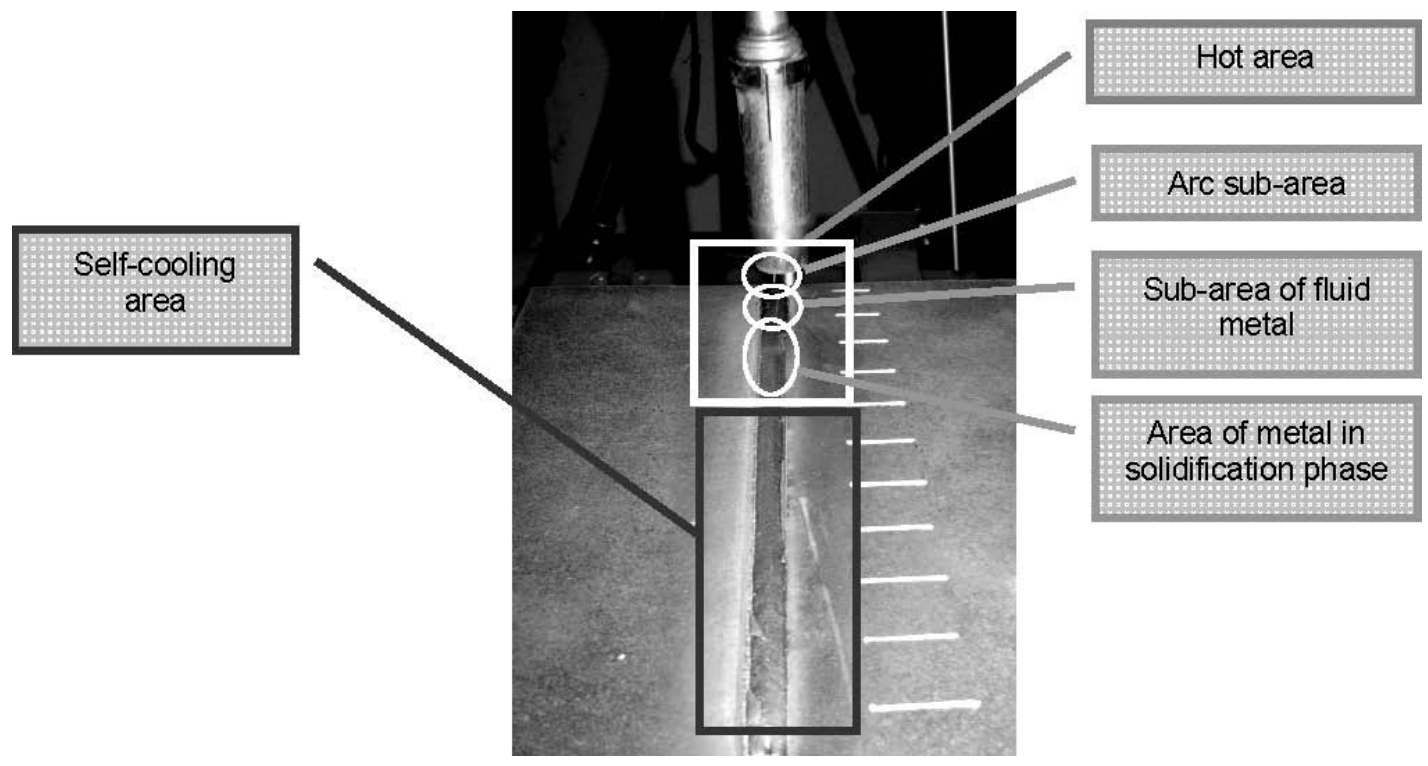

Fig. 1. View of a weld and observation areas

Synchronization of measuring, recording and analyzing data being gathered has been performed by software that constituted the second part of the system. This part has been elaborated with the use of LabView. In figure 2 one of system windows was shown. It made possible to monitor and control image recording. Elaborated procedures let us to record three images synchronously and process them by applying thresholding, filtering and $\mathrm{ROI}$ (region of interest) extracting. Image analysis has been based on identification of characteristic features of objects identified in images. Image recognition deals with determination of fault types and abnormalities occurring during the welding process. These operations were being performed on the basis of features resulting form analysis operations.

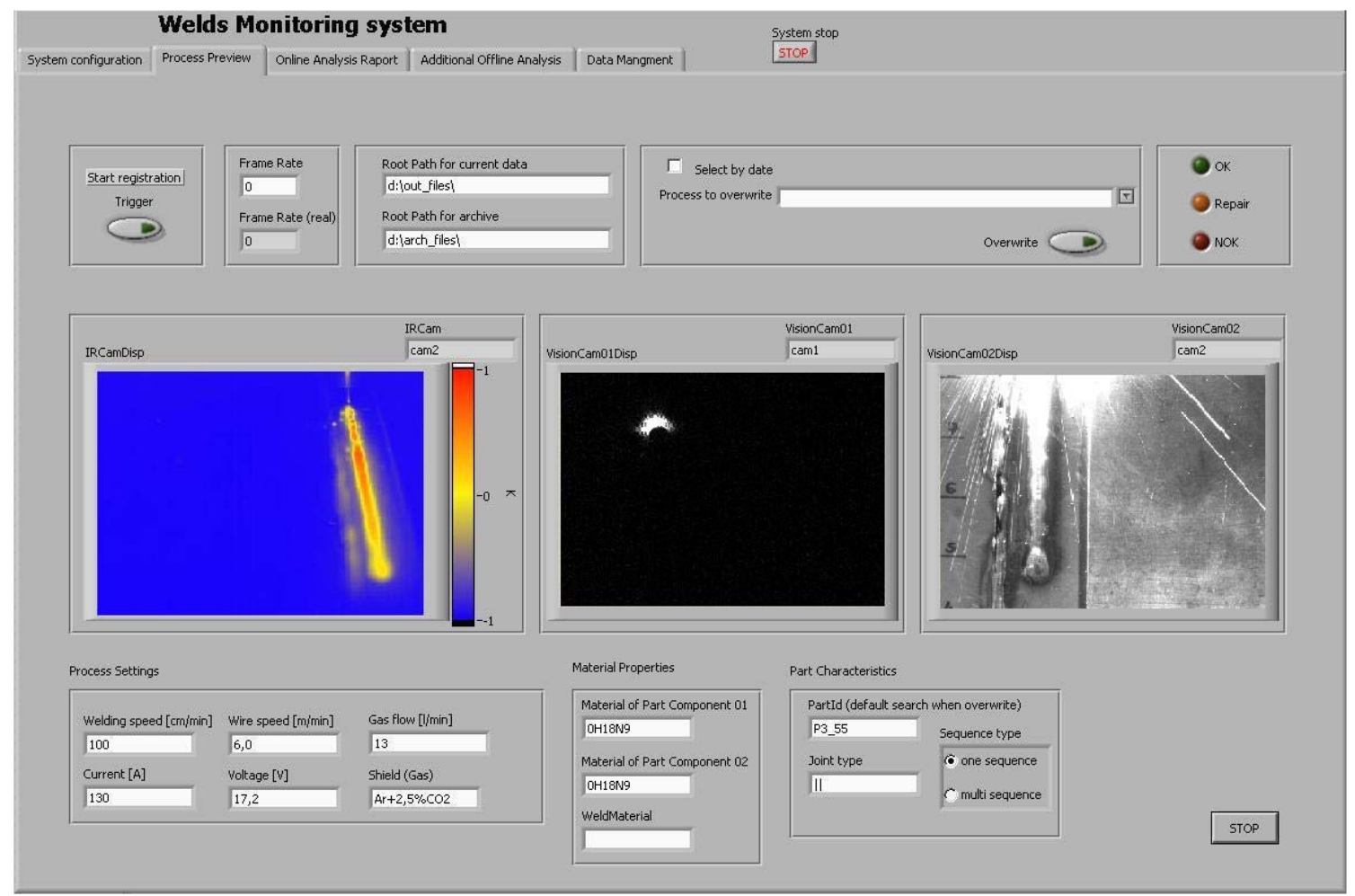

Fig. 2. User interface window. Module of image acquisition 
One of the most important module of the software part was database, which let us to gather and maintain huge sets of images as well as results of their analysis. Integral part of the database was pattern set that is result of numerous experiments performed under different conditions of welding process and different states of welded elements and their areas. Database module has been elaborated with the use of MySQL 5.0 Community server[12]. Data transfer between client application integrated with main module of the system and database has been based on ODBC interface that is controlled from LabView environment by means of procedures included in freeware library sql_LV [9].

\section{General description of performed experiments}

A prototype version of the vision system was tested in Laboratory of Welding Research of Silesian University of Technology. A laboratory stand was presented in figure 3. During the experiment one side butt welding was performed. Welded plates were made of $0 \mathrm{H} 18 \mathrm{~N} 9$ with thickness equal to $2 \mathrm{~mm}$ and the plate edges were beveled. The welding process was carried out in such a way that made it possible to observe typical welding defects. The fallowing cases were taken into consideration: lack proper distance $(\mathrm{S}=0 \mathrm{~mm})$, proper distance $(0 \leq S \leq 0,8 \mathrm{~mm})$, too big distance between $(S>0,8 \mathrm{~mm})$, varying width of gap between plates along the weld. Some impurities (e.g. oil, paint) were also introduced. In order to simulate abnormality the welding process parameters were being changed. An automatic welding machine and placements of cameras was shown in figure 3a. The second stage of system testing was performed under industrial conditions (figure 3b) where welding exhaust silencers production was observed. The welding process was carried out by means of an automatic welding machine. During the laboratory test plates were moved along the straight line and the device passing filled wire was stationary. In the second case the device was also motionless but elements to be welded were turned around their axe. The main goal of these tests was to acquire series of images and verify initial assumption related to placements of cameras, sources of lights as well as parameters of image recording.

a)

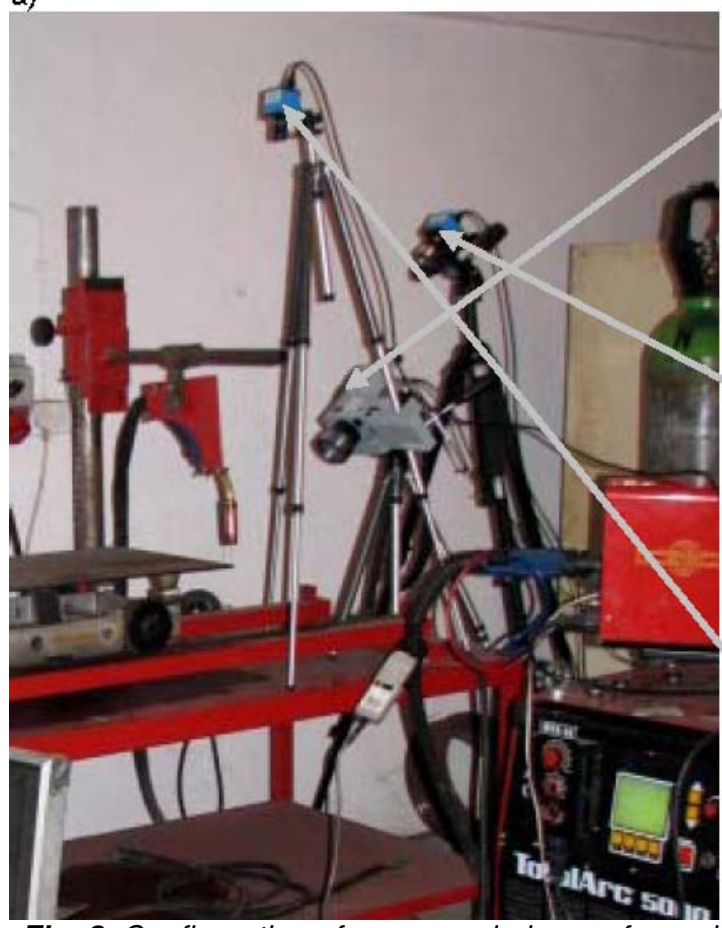

Thermovision camera observes arc area and hot area

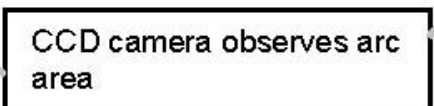

CCD camera observes weld self-cooling area b)

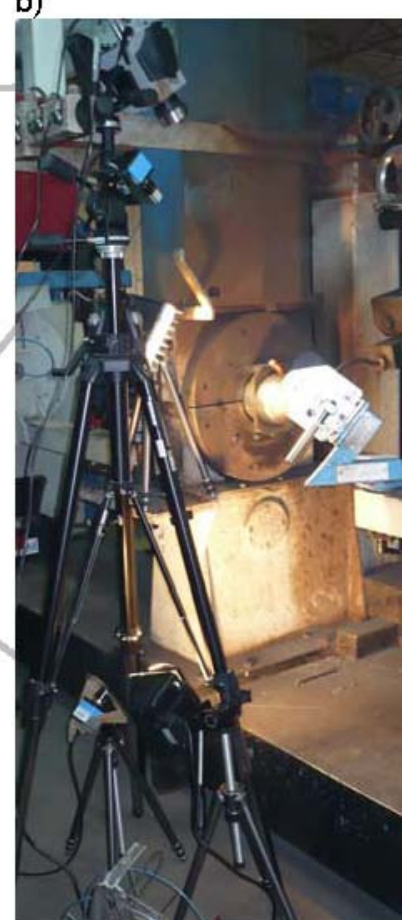

Fig. 3. Configuration of cameras during performed tests of the system: a) laboratory welding stand, b) industrial welding stand

Assessment of the welding process and welds has consisted on analysis of arc and self-cooling sub-areas. These areas has been visible in thermograms as well as in images recorded in visible light $[1,2]$.

\section{Image processing and analysis}

During the experiments images of resolution $320 \times 240$ pixels (infrared camera) and $786 \times 1024$ (ImagingSource CCD cameras) were recorded. In order to minimize processing time and focus elaborated analysis on specified objects some regions of interest $(\mathrm{ROI})$ were distinguished. At this stage it has been required to indicate them in images recorded by each of three enumerated cameras. These regions have involved respectively welding arc and joint (IR camera), welding arc (the first CCD camera) and joint (the second CCD camera). 
Processing procedures of images recorded by CCD cameras as well as IR camera were similar and consisted in converting color scale into gray, filtration and binarization. The main difference between these procedures were some parameters, especially values of binarization threshold. These values have been subjects of very detailed experiments, which goal is to adjust corresponding ROls were required. The first one let us to find corresponding images (presenting the same welded areas) within series of images. The second procedure allowed us to find details of corresponding ROls. Since CCD cameras observed the same time different welded areas, a single thermal image corresponded to two different images recorded by these cameras. Analysis of such selected images was based on comparison of parameters estimated on the basis of details visible in ROls. Determined $\mathrm{ROI}$ for three recorded images were shown in figures included within following section of the paper.

The core of the system has been a module of image analysis. As opposed to image processing, which has been performed by means of the same procedures for three types of recorded images, procedures of image analysis were elaborated separately for each type of images. All procedures included in the module operated on distinguished ROls only and the areas around ROls were omitted. Common characteristic of all applied methods, has been employment of context filtering but parameters of context operations were different. The goal of the analysis was to obtain a set of features that could be background for recognition abnormalities of welding process and faults of the weld. It has been assumed that a relevant set of selected features provides us with information enabling image classification into one of classes defined a priori. Classes that represent process abnormalities as well as welding faults. Classes have been defined by means of features estimated on the basis of ROls distinguished from proper images. In order to carry out the recognition stage an approach based on neural networks is going to be applied. Inputs of the network will be sets of features of estimated objects.

\subsection{Processing and analysis of thermograms}

Taking into account huge dynamic thermal changes of welding processes the observation of the process had to be planned carefully. Numerous factors related with the process and external environment were required to be taken into account. All of them significantly influenced thermograms recorded during the process. Fundamental considered disturbances were changes of emissivity of welded joints in temperature function and radiation reflexes in metallic, low-emission weld surface as well as welded elements [11]. Reflexivity observed during the process has been strongly dependent on placement of welded elements, camera and also a way welded elements were being moved while the device passing filled wire was stationary. In case of long, flat elements, which were moving along the straight line the influence of reflections was much greater than in case of round, symmetric elements that were turned around their axes. A placement of IR camera has played also a significant role. The observation in each direction that was different from the perpendicular one introduced additional unclear areas in the recorded image. The reason was limited depth of focus of an optical set of the IR camera. Apart from that, metal spattering generated additional areas in images manifesting themselves as hot areas. They were also dangerous for objective surface, so one must not neglect them. Protection against the spattering requires special protective filter, which made radiation reaching IR detector weaker. In order to obtain proper values of temperature compensation settings had to be taken into account. It should be emphasized that all enumerated factors influencing thermograms have been encountered during experiments described in the paper.

Despite these negative phenomena images recorded by IR camera could be considered as a huge source of information related to the welding process. They enabled us to identify changes of process states as well as states of the joint. However, considering such a complicated set of information like a thermogram, identification of abnormality of the process as well as detection joint faults was not simple. To extract valid information series of image analyses had to be applied.

A basic procedure employed in the case of these images was segmentation that stands for distinguishing some regions and objects, which could be analyzed by means of different, separately elaborated methods.

Results of such operations were shown in figure 4. Regions and objects were identified in selected ROls also shown in the figure. 


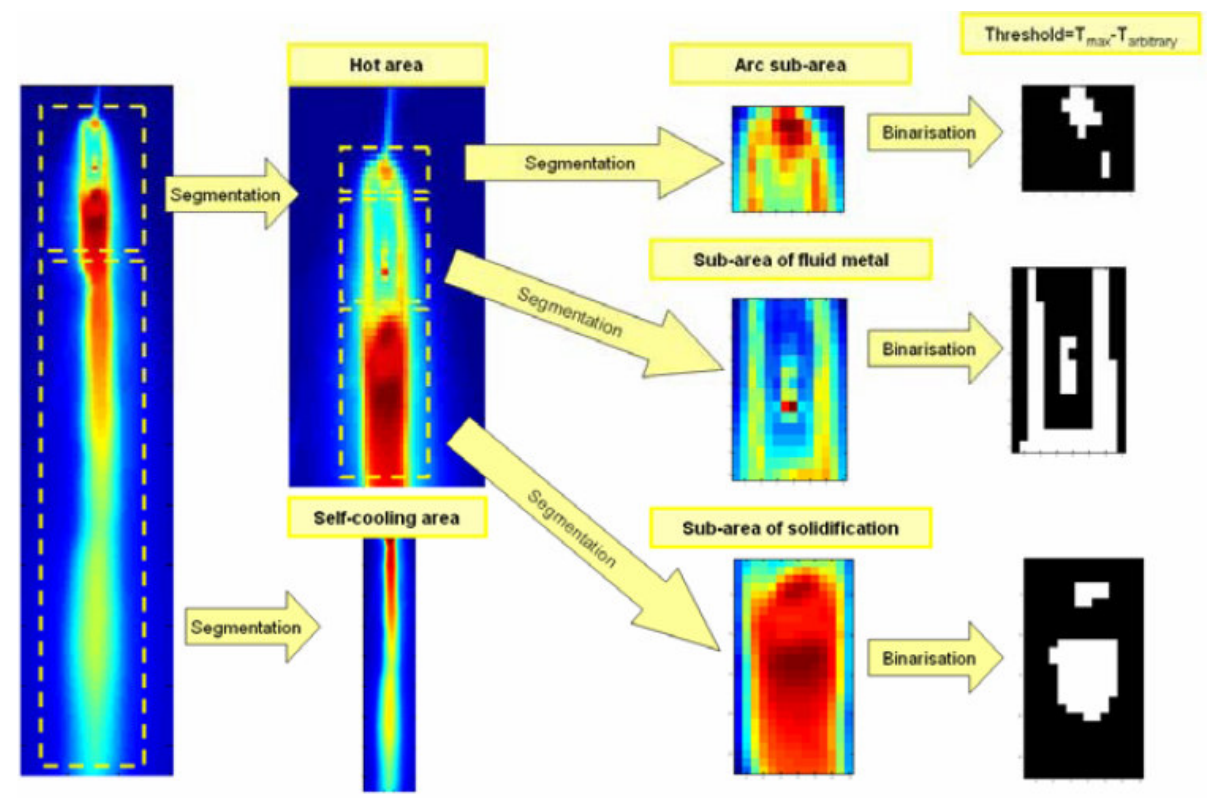

Fig. 4. A general scheme of dealing with thermograms

Observation of fluid metal made it possible to notice that the area was significantly cooler than solidification area. In fact the temperature of the first enumerated area was much higher than temperature of the second one. It was result of increase of emissivity which was accompanied with increase of temperature, thus decrease of $\mathrm{IR}$ radiation power which reached the camera. The red field noticeable also in this sub-area was apparently an effect of reflection of hot arc in fluid metal surface. It has been assumed that described phenomena systematically appear in recorded images and they were not taken into consideration. On the basis of initial research one stated that they did not influence result of assessment of welding process significantly. It was expected that these reflections can be considered as additional sources of diagnostic information related exemplary to irregularities of temperature resolution within fluid metal sub-area. An operation carried out directly after segmentation was image binarization. As previously it was performed within selected ROls. Determination of proper threshold value was considered to be one of the biggest problem of this operation. There have been no any clear rule considering this value. In the case of the research described in the paper the value has been assumed on the basis of experimental research. Result of binarization for selected ROls were presented in figure 4.

Analysis of such processed regions could be carried out with the use of numerous methods. Within the framework of the research several procedures have been tested. The first approach was based on estimation percentage values of binary image areas for pixels above assumed threshold. These changes were calculated relatively to whole area of $\mathrm{ROI}$ selected during segmentation. Tracking relative values of changes of field in time made it possible to identify process abnormalities that directly affected weld quality. This approach could be applied to arc and solidification sub-areas. Exemplary results of the procedures were presented in figure 5.

The second elaborated approach consisted in estimation of horizontal and vertical temperature profiles. They were calculated along straight lines which were perpendicular and parallel to the main axis of the weld. Result of the operation was shown in figure 8 . Such profiles could be treated as specific functions and statistically analyzed with the use of methods employed for impulse and transient signal estimation.

Additionally ordering the profiles according to duration of the welding process made it possible to acquire new images called profilograms (figure 5). Such plots provided us with information related to instability of welding process. 


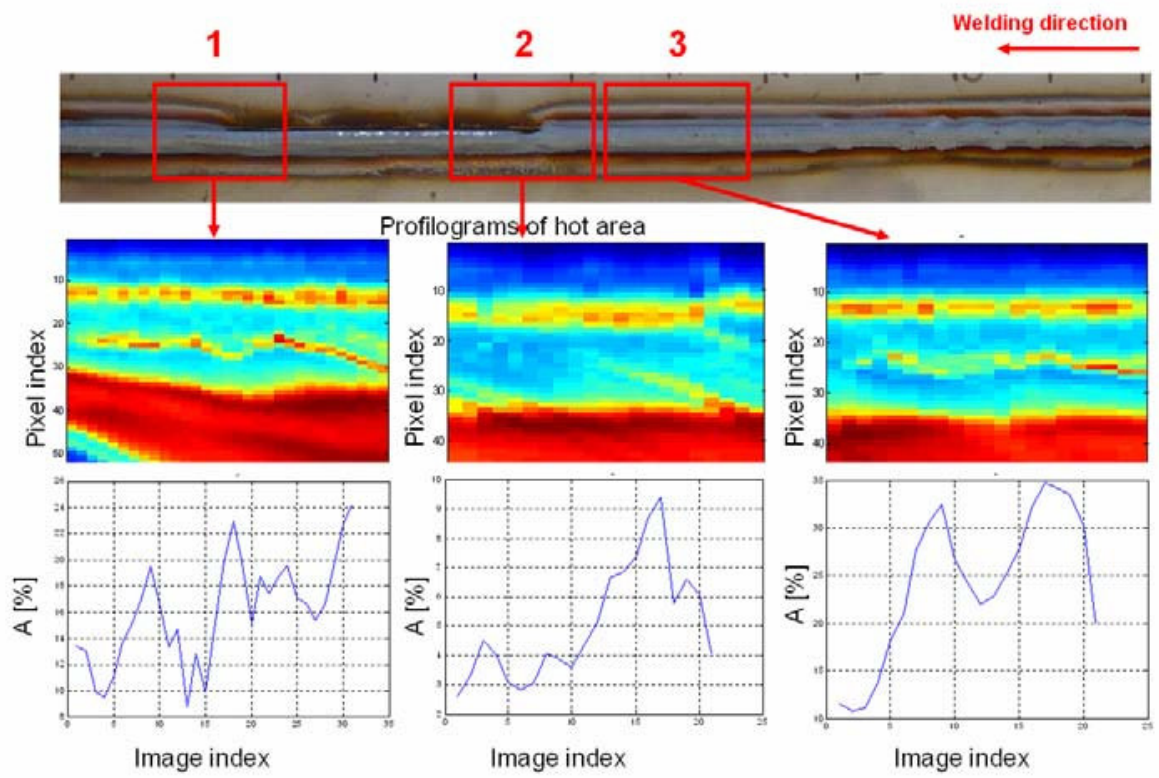

Fig. 5. Examples of analysis of thermogram of a butt joint

a)

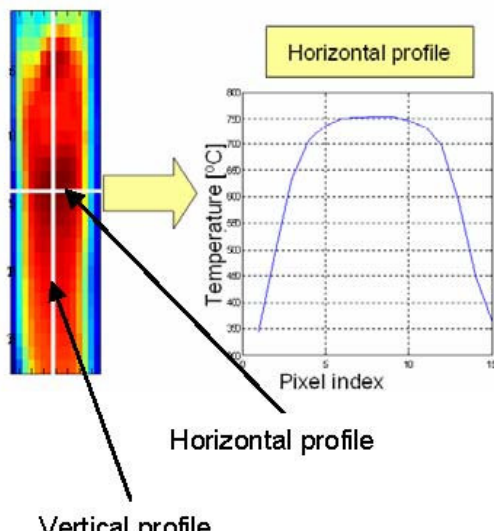

Vertical profile b)

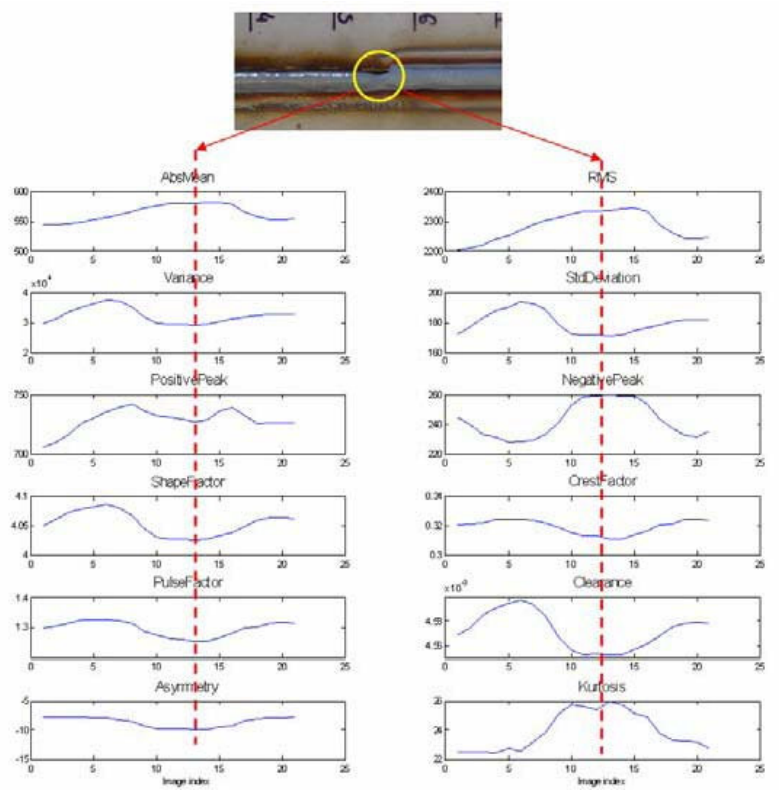

Fig. 6. A way of estimation of horizontal profile a) and exemplary results of analysis of horizontal profile b)

In figure 5 estimated profilograms for selected regions of a butt joint were presented. These profilograms were result of analysis of hot sub-area, for which values of parallel profiles were gathered. Below the profilograms values of relative field for binary images of solidification sub-area were presented. In the figures correlation between irregularity of width of the weld face and result of performed analysis has been clearly noticeable. In figure $8 \mathrm{a}$ thermogram of solidification area of the weld with horizontal and vertical profiles and temperature distribution along horizontal profile were presented. Figure $6 \mathrm{~b}$ has shown changes of selected parameters of the horizontal profile in time function. Significant changes of values of calculated parameters were observable.

\subsection{Processing and analysis of arc images}

Stability of the welding process has being estimated on the basis of assessment of images representing welding arc. During initial experiments numerous features were estimated, e.g. size of arc are, center of mass, lengths of arc in different direction, orientation, compactness, elongation and selected geometrical moments. On the basis of correlation analysis (figure 7) a set of relevant features has been distinguished. In figure 8 two 
exemplary features together with corresponding arc areas were presented. The features are center of mass and elongation factor that is defined as maximal diameter of identified shape divided by equivalent rectangle short side.

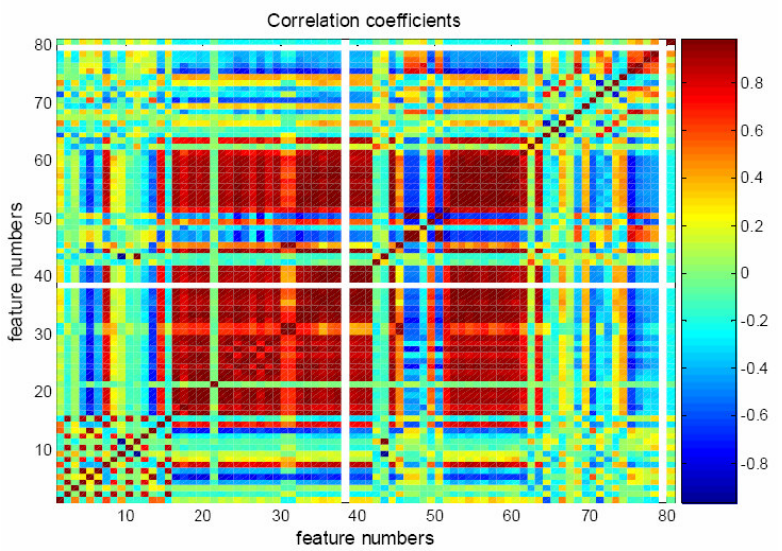

Fig. 7. Analysis of correlation between estimated features

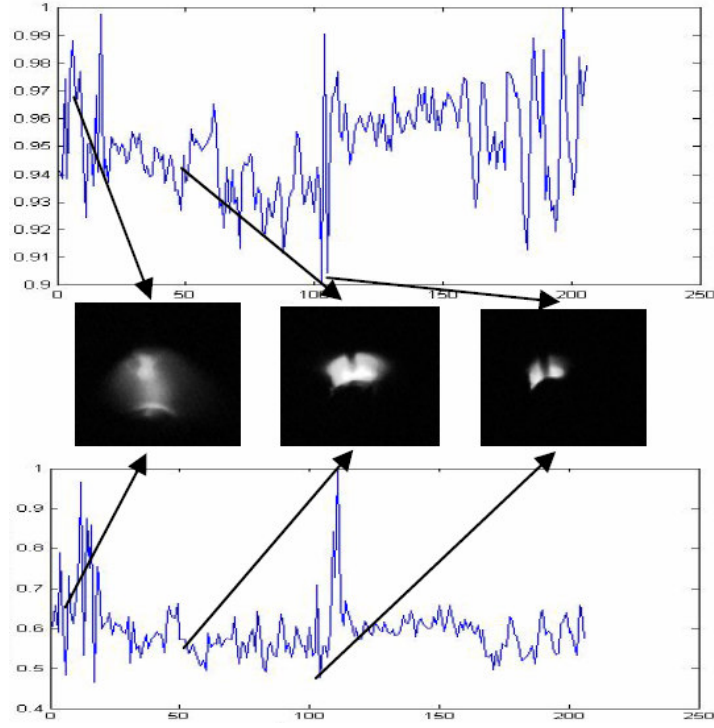

Fig. 8. Exemplary features and corresponding arc areas

Among other factors, the stability of the welding arc has been dependent on quality of elements being welded as well as welding parameters. In case of correctly prepared edges of welded elements the process was stable and deviations of arc and shape dimensions were small. During the welding that was not correctly performed, the process was instable. In order to estimate abnormalities of the process some pattern shapes of arc are going to be determined. They will be based features enumerated above.

Exemplary results of estimation of such pattern features (sizes of arc areas) on the basis of images recorded during welding process were presented in figure 9. In the figure two distinct areas have been visible. The first one corresponds to a correctly prepared surface and edges of welded elements, and the second one reflects changes of the arc observed in cases of different impurity. Exemplary images presenting stable and instable arcs were presented in figure 10. The second task of the system was to determine quality of welded joints. It is also important that this assessment was being performed during the welding process. A few commonly appearing faults have been identified.

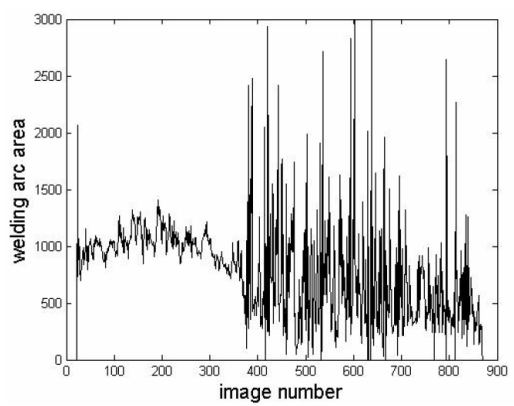

Fig. 9. The results of measuring the arc area
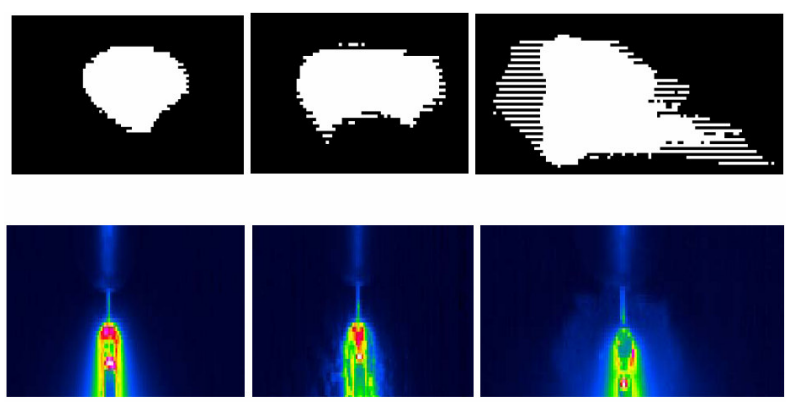

Fig. 10. Exemplary images of welding arc during the welding process

In order to provide faults detection and recognition a library of pattern images has been gathered. It was assumed that the application of the final version of the system enabled us to determine kinds of defects, their sizes and placement. These data has been possible to be established on the basis of thermal images that showed self-cooling process of welded joint (upper row in figure11). 

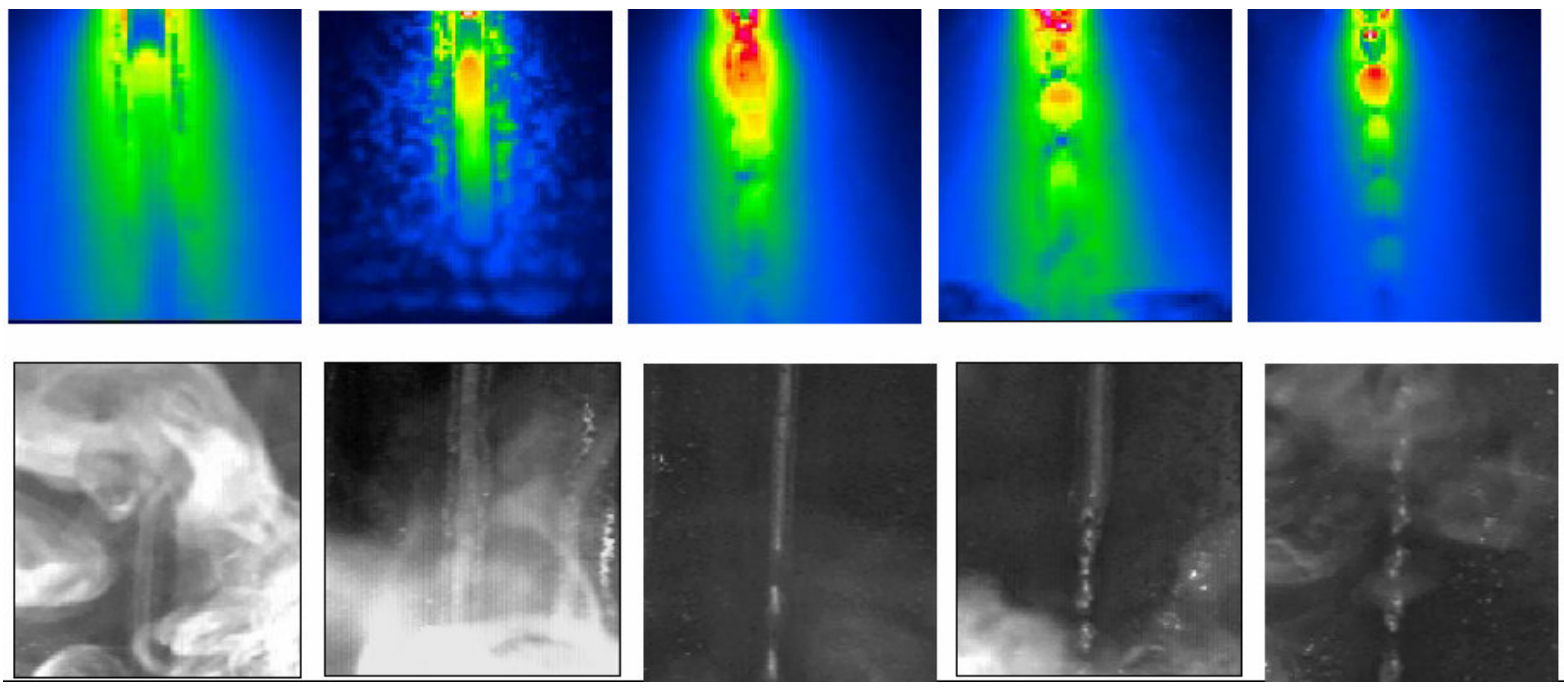

Fig. 11. Exemplary thermal images and images recorded by CCD camera of joints

Results of analysis of these images have been parameters characterizing joints. These parameters in combination with results of images recorded by one of CCD cameras (lower row in figure11) let us to estimate joints and detect their defects.

Images of arc sub-areas are binarized. Similarly to the binarization of thermograms the problem of this procedure was determination of proper threshold value. On the present stage of the research this value has been determined for whole series of images. It has been estimated on the basis of initial research [1]. Since, one common value for all images may cause loss of some diagnostic information the research related to automatic selection binarization threshold are still in progress. The approach to be applied has been based on analysis of local changes of brightness of pixels which have been placed on the border between arc and the background.

In the next step processed images were undergone to estimation of topologic features of arc area. Pixels which were characterized by higher values than binarisation threshold were only taken into account. Examples of such features were surface area, arc symmetricalness and circularity, Malinowska's coefficient [22] and also shape factors determined by lengths of two perpendicular axes. Observation of changes of these values let us to monitor and estimate process stability. Exemplary results of image analysis based on estimation of topologic features (surface area) recorded for stable and unstable welding processes were shown in figure 12.

a)

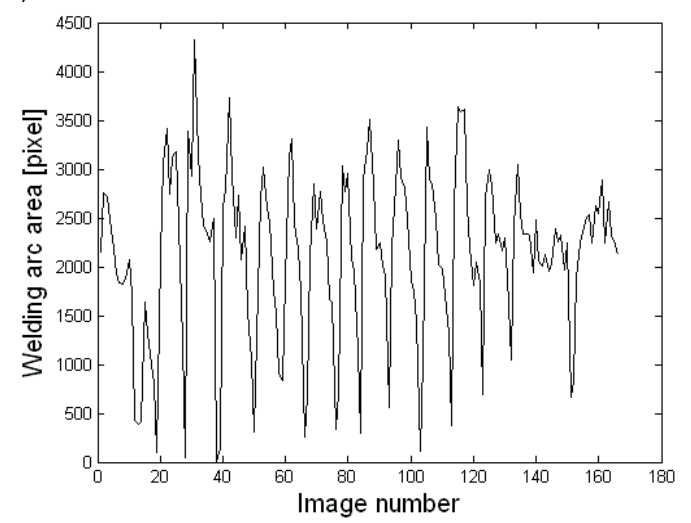

b)

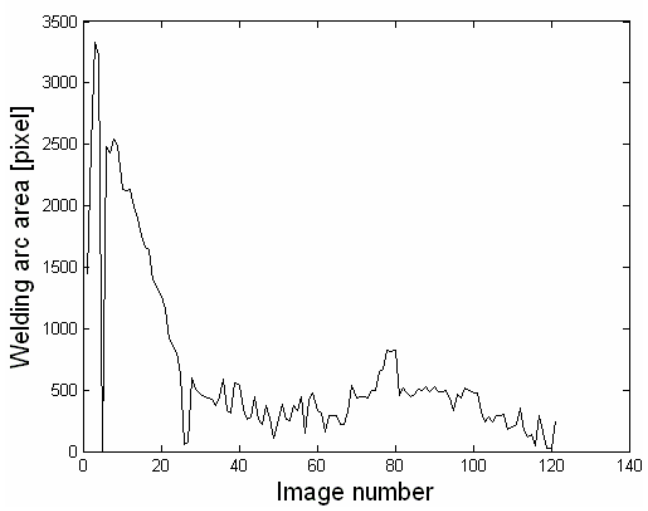

Fig. 12. Changes of arc sizes of for unstable a) and i stable b) welding process

\subsection{Processing and analysis of welded joint images}

In case of images recorded during performed experiments (figure 13) simple context and local (based on calculation of values of single pixels) procedures have been applied. They made it possible to identify such welding faults like: concavity of the weld, metal spattering, partial or lack of joint penetration. Applied procedures were based on calculation of squared values of pixels, normalization and context filtering. Results of employment of these operations were images and further sets of features that are going to be fundamentals for recognition procedures. 
a)

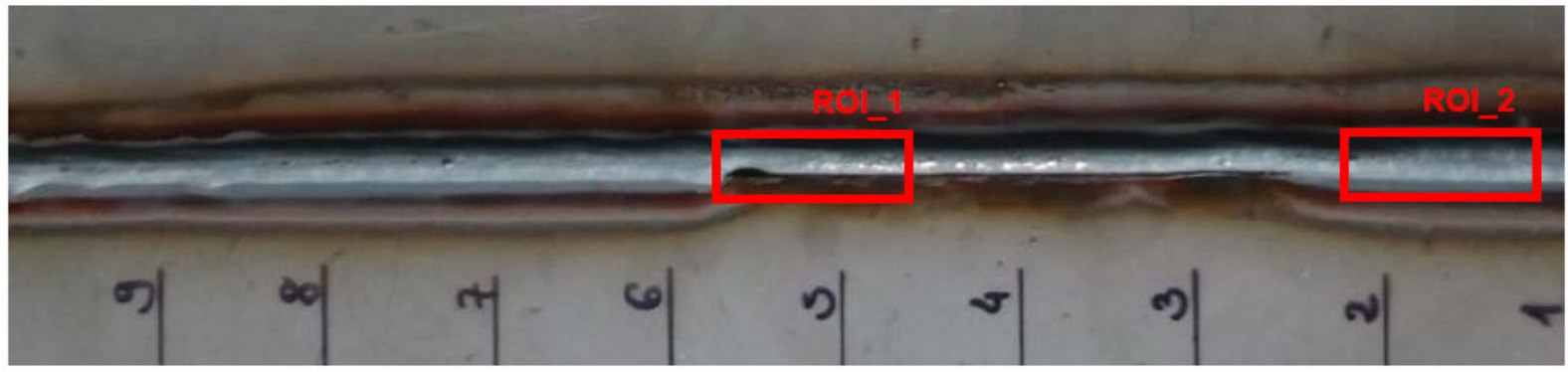

b)

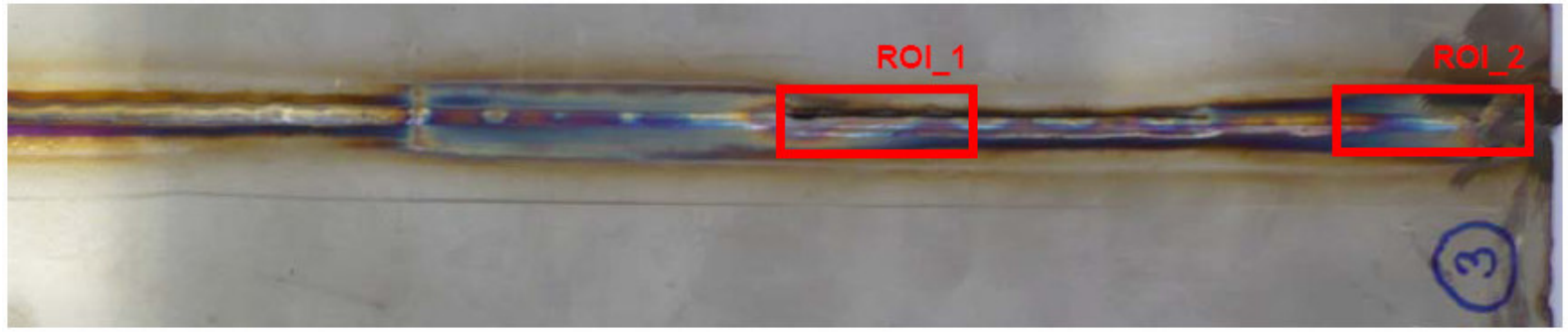

Fig. 13. Analyzed welded joint with ROls a) view from the face of the weld, b) view from the root of the weld

Examples of analysis presented in figures 14-15 exemplify images selected ROls (from figure 13). In figure 14 there has been a result of processing and analysis for correct joint (ROI_2), whereas figure 15 showed welding fault that was irregularity of width of the weld (ROI_1).
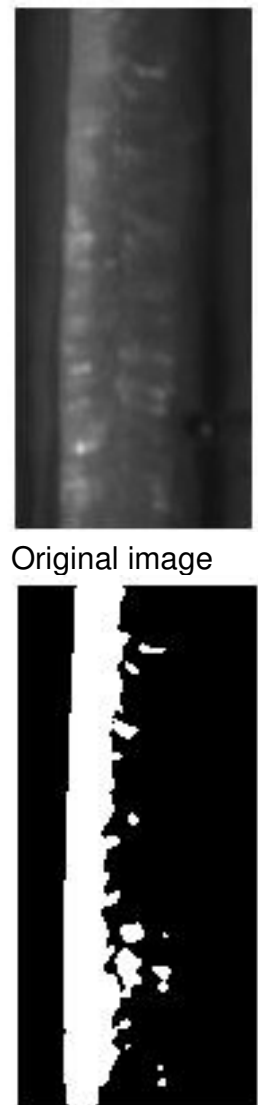

Image after binarisation

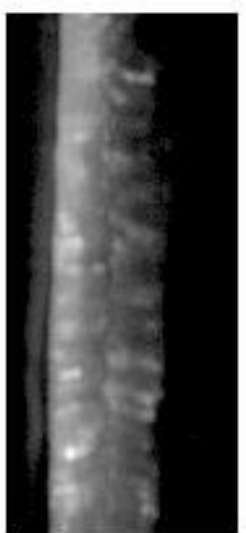

Image after normalization

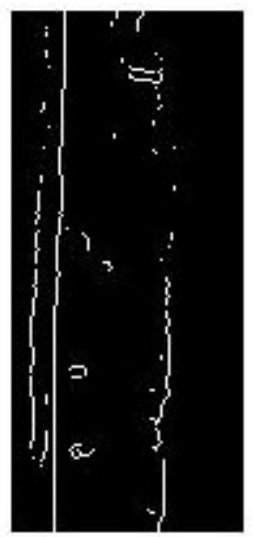

Image after Sobel filtering

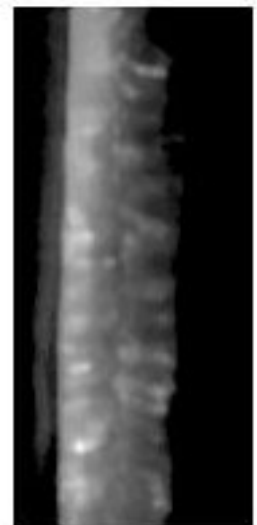

Image after mean filtering

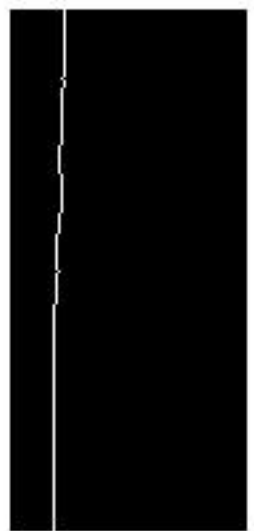

Image after context filtering

Fig. 14. Examples of application of selected operations of image processing of ROI_2 


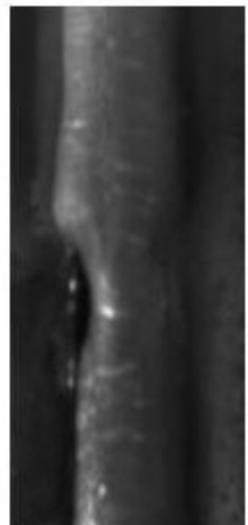

Original image

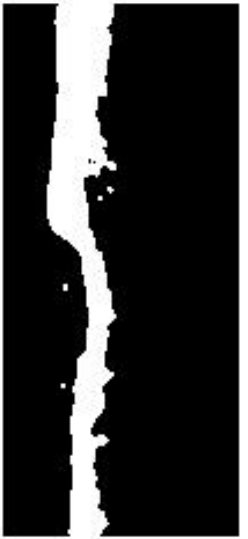

Image after binarisation

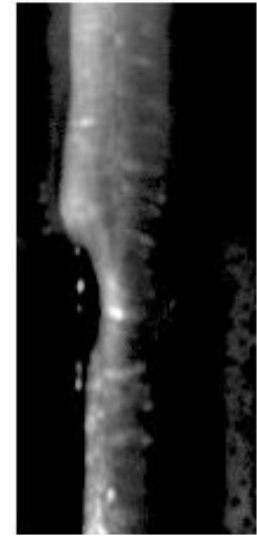

Image after normalization

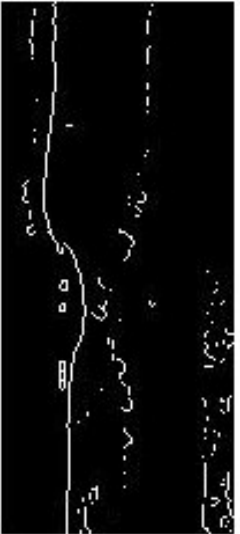

Image after Sobel filtering

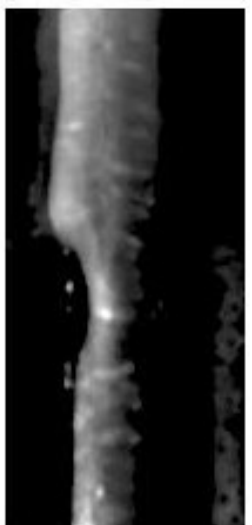

Image after mean filtering

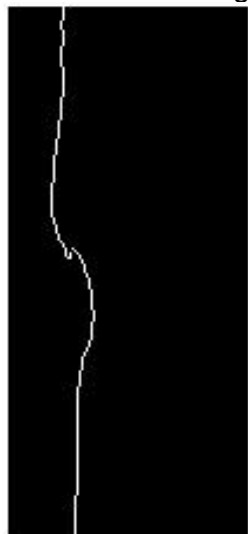

Image after context filtering

Fig. 15. Examples of application of selected operations of image processing of ROI_2

Because of changes of illumination coming from welding arc and light rays radiated by self-cooling area welded joint processing of discussed images was difficult. Examples presented in figures 14-15 were results of image analysis recorded without additional light sources. Since that only one edge of joint has been possible to be identified. Present research has been devoted to choice of proper illumination of the area involving the joint. Different illumination made it possible to extract both edges of the joint, what led to identification of their edges as well as symmetricalness of the joint. Procedure that was elaborated for this kind of images especially has been based on scanning the joint to look for outstanding fields or artifacts. Scanning was being conducted in two relatively perpendicular directions. During the scanning brightness profiles along distinguished straight lines were calculated. The approach enabled to identify width of face of the weld (figure 16a) and estimate rectilinearity of its edges, moreover detect welding faults (figure 16b). Examples of application of scanning procedure with the use of perpendicular and parallel to joint axis as well as profiles of light were presented in figure 16.

a)

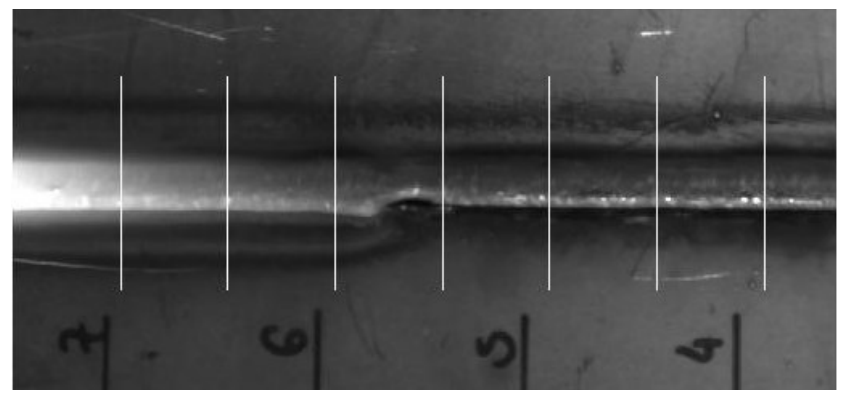

b)

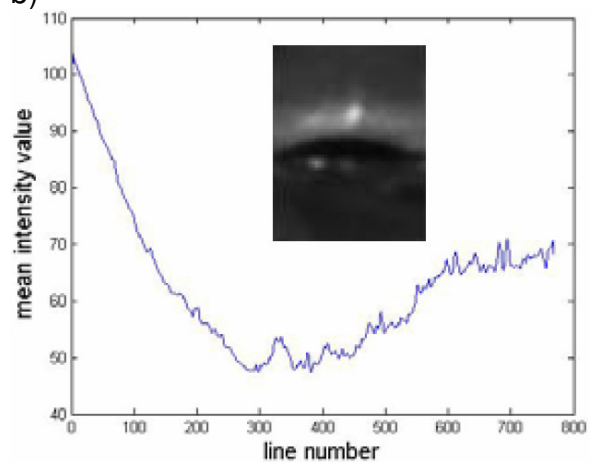


c)

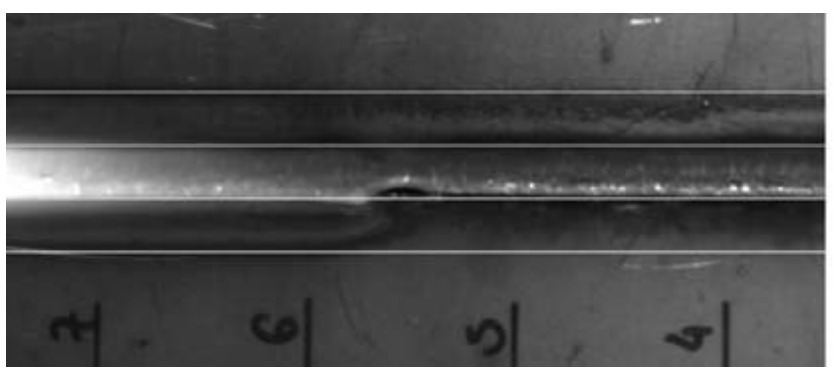

d)

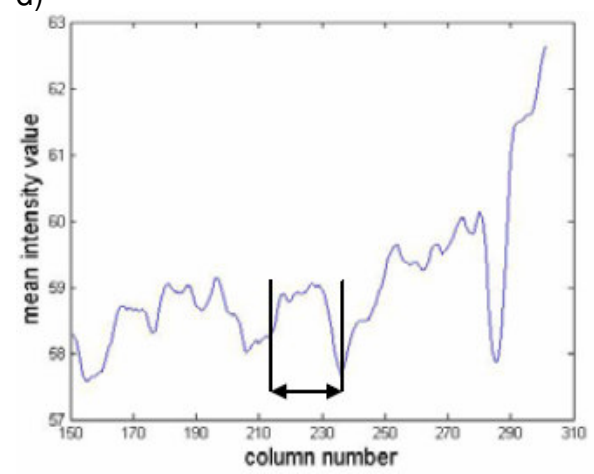

Fig. 16. Examples of a),c) application of scanning in two directions, results of scanning: b) identified welding fault d) estimation of width of face of the weld

\section{Conclusions}

In the paper elements of an approach to automatic control of welding process and welded joints were presented. Particular attention was paid to image processing and analysis. During the research presented in the paper numerous approaches were tried to be applied. Since characteristic properties of all three types of images recorded during experiments different methods of relevant feature extraction were required. To make the process of image evaluation easier and focused on some specific objects the first of image processing is determination of $\mathrm{ROIs}$ (regions of interests). At present stage of the research they are established during system calibration and they are preserved for all images recorded as an observation of a single welding process. Because of that objects identified within selected ROls are relatively uncomplicated we were able to apply simple geometrical features. Depending on the image type different set of features can be considered into account. To obtain optimal characteristics of identified objects correlation analysis was applied. Results are limited sets of relevant mutually not correlated features. They are going to be basis for definition of patterns representing abnormalities of the welding process as well as weld defects. These patterns and relevant features will be used in further steps of the research which is aimed at determination of quality of the welding process. Some image recognition approaches are planned to be applied.

\section{REFERENCES}

[1] Bzymek A., Fidali M., Timofiejczuk A.: Methods of image processing in vision system for assessing welded joints quality. Recent Advances in Mechatronics. Jabłoński R., Turkowski M., Szewczyk R. (ed.), Springer,258-262, 2007.

[2] Bzymek A.: Estimation of welding arc shape changes with the use of image analysis methods. Methods of Artificial Intelligence AI-METH 2007, Gliwice 2007.

[3] Cook G.E., Barnett R.J.: Automated visual inspection and interpretation system for weld quality evaluation, Industry Applications Conference, 1995. Thirtieth IAS Annual Meeting, IAS '95., Conference Record of the 1995 IEEE

[4] Czuchryj J.: Quality control of welding process, KaBe , Krosno, 2002. (In Polish)

[5] Czuchryj J.: Evaluation of welds according to European norms: systematics and reasons of occurrence of weld defects. Wyd.3, Biuro Gamma, Warszawa, 2003. (In Polish)

[6] Czuchryj J.: Evaluation of welds according to European norms: visual control. Wyd.2, Biuro Gamma, Warszawa, 2003. (In Polish)

[7] Fan H, Ravala N.K., Wikle H.C., Chin B.A.: Low-cost infrared sensing system for monitoring the welding process in the presence of plate inclination angle. Journal of Materials Processing Technology vol. 140, no 1: 668-675, 2003.

[8] Fidali M., Timofiejczuk A. and Bzymek A.:. A concept of vision system for assessment of welding process and welded joints. Konferencja "Diagnostyka Systemów i Procesów", Słubice 2007 (in Polish)

[9] Free LabVIEW SQL/ODBC. http://performancemicrowave.com

[10] Gibczyńska T., Rejman E.: Fundamentals of machinery design, welded joints, RWUPR, Rzeszów, 1993. (In Polish)

[11] Huang R.-S., Liu L.-M., Song G. : Infrared temperature measurement and interference analysis of magnesium alloys in hybrid laser-TIG welding process. Mater. Sci. Eng. A, 2006, doi:10.1016/j.msea.2006.10.069.

[12] Jamrozik W., Fidali M.: Database of a vision system of monitoring and evaluating welded joints. BDAS 2008, Bazy danych: Aplikacje i Systemy, Ustroń, 2008. (In Polish) 
[13] Kim J.S., Son Y.T., Cho H.S., Koh K.II.: A robust method for vision-based seam tracking in robotic arc welding, Proceedings of the IEEE International Symposium on Intelligent Control 1995

[14] Klimpel A., Szymański A.: Kontrola i zapewnienie jakości w spawalnictwie, Tom 1, Tom 2, Wydawnictwo Politechniki Ślaskiej, Gliwice, 1998.

[15] Mazur M.: Fundamentals of welding. Wydawnictwo Politechniki Śląskiej, Gliwice, 1998. (In Polish)

[16] Porębska M., Skorupa A.: Cohesion joints.Wyd.2,PWN, Warszawa, 1997. (In Polish)

[17] PN-EN ISO 5817. Welding. Welded joints of steel, nickel, titanium and their alloys (except of beam welding). Quality levels according to weld defects, PKN, April 2007. (In Polish)

[18] PN-EN 13018. Non-destructive inspections. Visual inspectionsBadania wizualne. General principles, PKN, October 2004. (In Polish)

[19] PN-EN 970. Welding. Non-destructive inspections of welded joints. Visual inspections, PKN, August 1999. (In Polish)

[20] PN-EN 1289. Non-destructive inspections of welded joints. Penetrative inspections of welded joints. Acceptance level, PKN, December 2000. (In Polish)

[21] Smith J.S., Balfour C.: Real time top-face vision based control of weld pool size, An international journal Industrial robot, No 32/2/2005

[22] Tadeusiewicz R.: Vision system of industrial robots. WNT, Warszawa, 1992. (In Polish)

[23] Węglowski M. S.: Visible radiation as an useful signal in monitoring of welding process. Pomiary Automatyka Robotyka 10/2006 (In Polish)

[24] Xu D., Wang L., Tan M.: Image processing and visual control method for arc welding robot, Proceedings of the IEEE International Conference on Robotics and Biomechanics, Shenyang, China, 2004

[25] Yamamoto M., Kaneko Y., Fujii K., and others.: Adaptive Control of Pulsed MiG Welding Using Image Processing System, IEEE, 1988. 